\title{
Being Deaf in Mainstream Education in the United Kingdom: Some Implications for their Health
}

\author{
Mike Berry \\ Institute of Leadership, Royal College of Surgeons in Ireland, Ireland
}

Copyright $(2017$ by authors, all rights reserved. Authors agree that this article remains permanently open access under the terms of the Creative Commons Attribution License 4.0 International License

\begin{abstract}
This paper explores the issue of deaf children in mainstream education and the implications this has for their health. Currently more than 48,000 children in the UK are classified as deaf with some $85 \%$ taught in mainstream schools although they are significantly educationally underachieving. The vulnerability of deaf children and some of the difficulties they face are highlighted. An outline is provided of the nature of deafness and the Deaf Community, together with a description of cochlear implants and of British Sign Language. Some of the issues relating to the need for assessment, treatment and support for deaf children are discussed, including increased risk of sexual and physical abuse. Possible professional roles for psychologists are identified.
\end{abstract}

Keywords Children, Deafness, Abuse, Mental Health, Education

\section{Introduction}

\subsection{Introduction to Hearing Loss}

The aim of this paper is to explore the issue of being deaf in mainstream education and the implications for deaf school children's health in the UK. The emphasis is on the United Kingdom rather than the developed world because of the complexities of the UK's legal and education systems. While deafness or the American preferred term "with hearing impairment" is universal, the way it is dealt with varies widely worldwide. The term 'deafness' here is used to describe all degrees and types of hearing loss, whether conductive, sensorineural or mixed. In conductive hearing loss, the conduction pathways for sounds to reach the inner ear are affected. This usually influences nearly all frequencies of hearing evenly. Sensorineural hearing loss results from damage to the delicate sensory hair cells of the inner ear or the nerves which supply it. The loss can range from mild to profound. A mixed hearing loss occurs with both conductive and sensorineural loss resulting in lasting damage to the ear. Hearing loss may arise from a wide range of acquired or hereditary causes, including in utero damage from drugs or infections [1].

Deafness (from the Dutch word "Doof") is being used here to describe hearing loss, which corresponds to hearing level of $95 \mathrm{~dB}+$ (the quietest sound that can be heard is $>95$ decibels). Severe hearing loss is 70-94 dB, the equivalent of the sound from a lawnmower or airplane nearby, for moderate hearing loss is 40-69 $\mathrm{dB}$, the sound level of a baby crying or dog barking causing difficulty following speech even with hearing aids. Most hearing people can hear sounds ranging from 0 to $140 \mathrm{~dB}$ with whispering at 25 to $30 \mathrm{~dB}$, talking usually between 45 to $60 \mathrm{~dB}$. Sounds louder than 90 $\mathrm{dB}$ can be uncomfortable while some heavy metal bands can register $110 \mathrm{~dB}+$. Levels above $120 \mathrm{~dB}$ can be painful resulting in temporary or permanent hearing loss.

\subsection{Methodology}

A detailed review of the various WebPages catering for the deaf population was undertaken such as actiononhearingloss.org.uk; asha.org; cdc.gov; ncbddd; childrenmentalhealthweek.org;

cmft.nhs.uk/childrens-hospitals; fda.gov; gosh.nhs.uk; hearingsolutions.ca; ndcs.org.uk; nidcd.nih.gov; occupytheory.org. Initially a literature search of various databases was undertaken using key words deafness and school children further searches were undertaken on important authors, plus a review of the major papers published over the last three decades in addition to contact with various experts in the field concentrating specifically on school children rather than pre-school.

Of note is the work of CRIDE [2] a consortium bringing together a range of organizations and individuals with a common interest in improving the educational outcomes achieved by deaf children through research. Representatives include: the British Association of Teachers of the Deaf (BATOD), City University of London, the Ear Foundation, the Ewing Foundation, the National Deaf Children's Society, 
the National Sensory Impairment Partnership (Nat SIP), Frank Barnes School for Deaf Children, Mary Hare School, the specialist education service for deaf children in Kent, Norfolk and the Highlands, University of Edinburgh, University of Leeds and UCL. The search highlighted the limited work on deaf children's health issues compared to hearing children.

\subsection{Estimates of the Prevalence}

Estimates of the prevalence of deafness in children must be treated with caution as they vary considerably depending on the hearing loss thresholds used in different studies and the age of the sample. One of the problems in reviewing deaf educational provisions is that legal requirements vary widely worldwide, so unless mentioned, data will relate to the UK only. Fortnum et al. [3] estimate the prevalence of permanent childhood hearing loss in the United Kingdom with adjustment for under-reporting, the combined prevalence for moderate, severe and profound hearing loss was 10.7 per10,000 for three year olds and 20.5 per 10,000 for children aged 9-16. For those with profound hearing loss, the figure was 2.7 per 10,000 for three year olds and 4.4 per 10,000 for those aged 9-16. CRIDE's [2] defined children and young people up to the age of 19 with sensorineural and permanent conductive deafness from mild to profound.

Currently some 900,000 adults in the UK are classified as 'severe or profoundly deaf' and more than 45,000 children are classified as deaf [4]. Approximately $85 \%$ of deaf children are taught in mainstream schools [5]. CRIDE's [2] survey reported a total of 48,932 deaf children in the UK on 31st January 2015. For those children who are born deaf; a prevalence rate of approximately $20 / 10,000$ is indicated [2]. Based on responses from 126 out of 132 services, the total number of deaf children in England was 41,261. It is noted that in $2011,37,414$ children were identified as being deaf, indicating a $10.3 \%$ increase in five years. The smallest service reported 70 deaf children within in their boundaries. The largest reported 1,466 deaf children. The average number of deaf children belonging in each service was 327 . Based on 132 services, it is obvious that different services have considerably different pressures exerted on them to provide service for deaf children. These figures suggest that the School Census continues to significantly under-record the number of deaf children. The 25,367 deaf children identified by the School Census amounts to $61 \%$ of the 41,261 deaf children identified by CRIDE.

The usual way to write about $\mathrm{D} /$ deaf people is to focus on the fact that they do not hear. As such there is a risk that everything they are and everything that they will do will be interpreted in this context. Deafness therefore can in some circumstances be seen as 'problematic'. In the past, deaf people were viewed as being disabled and of limited intellectual ability a perception reinforced by clinical as well as educational literature, maintained by a lack of information on deafness and the use of inappropriate methodology.

\subsection{Underachieving}

One of the many reasons why deafness is an issue for psychologists is the knowledge that deaf children are underachieving. For example, many deaf children will be unemployed and have a higher rate of mental health problems in adulthood [5]. Based on their survey of services for deaf children [2]; they are among the most vulnerable and educationally dis-advantaged children in the UK. The Department for Education [6] indicated that in England in $2015,41 \%$ of deaf pupils obtained five GCSEs A-C grades (the highest three grades in the General Certificate of Secondary Education), including English and Maths, compared with $64 \%$ for 16 years old schoolchildren in general [6]. These figures need to be treated with care [2], who identified over 41,000 deaf pupils compared with the Ministry's census figure of approximately 24,000 . Basically, the School Census is failing to capture $39 \%$ of deaf children.

The National Deaf Children's Society [5] raised the issue of a lack of accurate Government data on deaf school leavers as this has major implications for funding of services. They also reported that UCCA [7] ${ }^{1}$ indicated 780 deaf applicants in 2015 were successful in their application for a place at university compared to over 400,000 hearing students. NDCS [5] indicated that there is no data available for UK deaf children's 'A' level results ${ }^{2}$.

While some UK universities have deaf units, none actually provide an education in BSL. In America, deaf students can aim and achieve a university education using American Sign Language (ASL) by attending Gallaudet University, the world's only university for the deaf. However it has had political problems in the past when hiring a hearing president, who it was thought did not understand the deaf culture (www. gallaudet.edu/about/history-and-traditions/deaf-president).

NDCS [5] highlighted the lack of post 16 year old work histories for deaf children in the UK making it difficult to advocate on their behalf. Historically, many deaf students leave Senior School with poor academic or vocational qualifications [5]. Usually faced with employment in non-deaf environments and such conditions can mean rejection, loneliness and isolation from work colleagues who lack an understanding of deaf issues.

In the past, deaf children in the UK were commonly educated at Schools for the deaf, however, most have been closed down and $85 \%$ of deaf children are educated in mainstream schools [2] including $7 \%$ at schools with special provisions. Some $21 \%$ of deaf children were recorded as having additional (undefined) educational needs [2]. The implications for deaf children include disassociation from their school environment because of the loss of background sounds, which can lead in more severe cases to depression. In most cases of profound deafness, speech is likely to be

1 UCCA, the Universities Central Council on Admissions, provides a 'clearing house' for university undergraduate applications in the United Kingdom.

2 'A' levels are usually taken by students for university entrance in the UK. 
affected, adding to communication problems and a lack of confidence resulting in restrictive social contact. Educational trips may be limited because of a lack of facilities (e.g. a 'loop system' to enable them to follow lectures or speech in meetings) or an interpreter to sign for them. Deaf children are at greater physical risk in public places and schools due to a lack of visual/tactile alarm systems.

\subsection{Communication}

Over $90 \%$ of deaf children are born to hearing parents with minimum experience of deafness or knowledge of how to communicate with a deaf individual [8]. A deaf child in a hearing family can feel stigmatized and socially isolated especially if the family does not learn sign language. A lack of communications can affect a child's development and make a child vulnerable to physical, emotional and sexual risk of harm as well as suffering educationally. It could be argued that parents and teachers not using signing are restricting a child's development, while signing would increase the child's self-esteem. Historically, Moores [9] argues that "rejecting sign language is rejecting the child", whereas accepting sign language should produce greater self-esteem. Gregory [10] found that in hearing families who signed, in approximately $50 \%$ of cases it was the mother who was the main signer and $50 \%$ of occasions it was a sibling but very rarely the father. The mother becomes the interpreter for the father, which affects the family dynamics and his child's self-esteem. Historically, the importance of the role of the father in a child's development is well known and is a major predictive factor in offending [11-12]. Families facilitating language development and communications skills are essential for deaf children. At social and family occasions, it is unlikely that everyone will sign, so young deaf children can feel left out and be embarrassed at attempts to involve them. However, if the whole family is deaf, the child is more likely to become part of a close knit, supportive Deaf Community, where they will be appropriately socialized and may be more protected from vulnerability and victimization.

\subsection{The Deaf Community \& British Sign Language (BSL)}

The age of onset and degree of hearing loss significantly affects an individual's communication preferences, language acquisition and cultural identity [12]. Prelingual deaf children are more likely to use sign language to communicate and identify within a distinct Deaf culture than those who acquire postlingual deafness. The term Deaf is used to identify individuals who belong to the Deaf community with British Sign Language (BSL) being their preferred language. The term deaf includes members of the Deaf Community unless specifically writing about the Deaf community, when a capital D is used.

Sign language was first documented in the UK by Bulwer
(1644). In the USA, until 1940, deaf people were regarded as 'legally incompetent'. In the UK, the case of an accused 'deaf mute' named Pritchard in 1836 resulted in 'Unfit to plead' being established [14].

While co-existing within the wider hearing world, the Deaf community has experienced high levels of social exclusion [15]. The Deaf community has suffered a great deal of misunderstanding over centuries, resulting in a history of misdiagnosis and inappropriate treatment by mental health professionals. For the Deaf community, BSL is as well designed, complex and sophisticated as any spoken language. BSL was legally recognized in the UK in 2003. Action on Hearing [16], suggest that there are between 50,000 and 70,000 people who use BSL, however it has been suggested because of a large census under-reporting it could be in excess of 100,000 [17]. While, over 5,500 (12\%) deaf children live in homes where neither English nor Welsh (another regional UK language) is the first language [2]; this adds considerable difficulties for deaf children trying to comprehend two or even three languages if they use BSL.

Within the psychosocial model, membership of the Deaf community has demographic, psychological, linguistic, political and sociological dimensions. The UK's Deaf community shares common experiences, beliefs, values and norms through a common language (BSL), and a shared culture. Such membership can enhance self-esteem and development of a positive self-concept. Sessa and Sutherland [18] supported the argument that spoken or signed early language acquisition is a protective factor against mental disorder with education as a means to prevent deferred development and improve mental health outcomes for deaf children. They argued the major factor in a child's potential mental health was how the child, their family and the community respond to the child's deafness.

However, $90 \%$ of children do not access BSL in childhood, and therefore do not acquire the ability to communicate until later in adolescence [2]. Humphries et al. [19] reported that signing can promote spoken language acquisition. Most deaf school leavers aged 16 or 17 have a reading age of 8-9 years [20], a figure that has not changed much over the years. Many deaf children acquire 'coping strategies' throughout their childhood and adolescent years whereby they will falsely give the impression of understanding what is being said. Deaf children will give out cues (nonverbal communications) as though they fully understand [21], which can be quite misleading especially in a strange environment. An advantage of being a member of the Deaf community is they usually have access to sign language as their first language; D/deaf children with $\mathrm{D} /$ deaf parents have less mental health problems [22]. The acquisition of understanding, beliefs, and identification of feelings, attitudes, social skills and awareness of choice is often limited in deaf children. It could be argued that religious needs may not be met in the British school system for many deaf children even though religious studies are compulsory under the Education Act [23]. 


\subsection{Cochlear Implant}

Cochlear implants have resulted in the development of hearing in many deaf children. Fortnum et al. [24] argue that children without implants do less well than those with implants in the classroom. Implants have improved communications leading to improved social relationships with peers [25]. Kent [26] reported that individuals with a hearing disability were more likely to report feeling and/or experiencing loneliness than those with hearing. Many adolescents have a constant desire to be perceived as 'normal', and not having 'hearing' problems [27] because they are very aware of the power differentials between themselves and the 'dominant' hearing culture leading to marginization [28]. With improved hearing comes the chance of developing 'good' spoken language [29] and possible better health. Mackay [30] provided a detailed review of cochlear implants including highlighting the relationship between autism/ASD and deafness. He emphasized the need to be aware of the relationship between being deaf and experiencing symptoms of Autism/ASD. Autism is about seven times more common in deaf children than in hearing children [31]. Sessa and Sutherland [18] argued that it is critical that professionals undertake accurate and early diagnosis of autism in deaf children.

Implants are increasingly becoming the norm with the argument that the earlier the better for auditory and verbal development [32]. Providing implants within the child's first 12-36 months creates the optimum chance of achieving and maintaining age appropriate spoken language skills during primary school years [33]. On 31st December 2012, over 324,000 people worldwide had received implants [34]. Indicative of its acceptability; Australian Graeme Clark, designer of the cochlear implant, was awarded the $\$ 500,000$ Russ Medal (the Nobel Prize for engineering) in 2015. Approximately 58,000 American adults and 38,000 children have received an implant [34] with over $70 \%$ of profoundly deaf British children having had them fitted [35]. The total maintained cochlear implant population in the UK at the end of March 2015 was 13,015 [36]. While there are many positive aspects of cochlear implants, however the USA's Food and Drug Administration's webpage (www.fda.gov) highlights some of the negative aspects such as general anesthesia risks associated with any medical process. Risks from surgical procedures include injury to the facial nerve; meningitis (infection of the brain's outer lining) and Cerebrospinal fluid leakage. Perilymph fluid leakage; tinnitus; numbness around the ears are also risks, as is the body rejecting the implant (Reparative granuloma). Funds upwards of $\$ 50-100,000$ may be required while the process is free under the UK's Health Service's provisions. While many are positive about cochlear implants, it could be argued that it poses a threat to the new generation of users who will no longer feel the need to join their local Deaf Community and as such it could reduce membership.

Not all deaf people want to join the hearing world with some perceiving implants as a threat to their culture and have not allowed their deaf children to have implants [37]. While much has been written about deafness and the use of implants, less is known about social confidence experienced by children. Implants can help deaf individuals improve their hearing but cannot cure deafness and some children may hold unrealistic expectations for themselves resulting in later feelings of low poor self-esteem and disappointment [18]. Berry and O'Rourke [38] explored Deaf, cochlear implanted and hearing male adolescents' differences in social confidence levels and found implant users demonstrated lower social confidence especially when in the company of Deaf males. Irrespective of age, individuals benefit from implants including those who are over 65 [39]. Bathgate et al. [40] have produced a guideline for psychologists working in implants teams.

\subsection{Specialist Teachers of the Deaf}

Deaf children have differing educational requirements compared to hearing children; they need to be fully assessed by a Specialist Teacher of the deaf and preferable by a Psychologist. The role of Specialist teachers is supporting deaf children and acting as a resource for classroom staff and Teaching Assistants to empower them in teaching in a deaf awareness manner. However, each visiting Teacher of the deaf in the UK is working, on average, with 42 deaf children with many in excess of 60 per teacher [5] while CRIDE [2] reported an average of 47 in 2015; such vast numbers challenges the whole concept of individualized educational support. The distribution of deaf children is not constant nationwide and some educational services are supporting ten or less while others over 200 children. This very wide ranging prevalence covers 132 service authorities thus service provisions varying widely for deaf school children depending where they live. Some deaf children in mainstream schools are being supported by Teaching Assistants, most who have little experience of deafness and have received insufficient training in how to cope with deaf children. It would appear that very little attention to deaf children's educational needs is considered during official visits $^{3}$ [8]. Due to limited funds that some State schools are not gaining access to specialist skills available in adjoining authorities ('postal code lottery'4) with negative implications for children's mental health [2].

\section{Mental Health}

\subsection{Mental Health Issues}

Deaf children experience behavioral or mental health problems covering a wider range of issues such

\footnotetext{
3 UK schools are regularly subject to thorough official assessment to evaluate their functionality (OFSTEAD).

4 A slightly derogative term implying where you live is more important than your needs for various services: the USA equivalent would be 'zip code'.
} 
cyberbullying, physical and psychological bullying; stress; educational problems including learning difficulties, school phobia, the influence of ADHD; the effects of being on the Autism Spectrum Disorder; depression including suicidal ideation; OCD; and physical health problems as well as eating disorders. In addition, deaf children may experience difficulties trying to communicate with their family doctor and even counselors who are not 'deaf aware'. Some of these problems may well result in anger outbursts that require anger management. Gutman et al. [41] reported on their study of approximately 20,000 families that over $10 \%$ of eleven year olds experience severe mental health problems as reported by their parents. Their results indicated that a child from a traditional professional postgraduate married parental home was some 4.5 times less likely to be perceived as suffering mental health problem compared to a mixed ethnic child of a unemployed low income family (17\% prevalence). Boys were twice as likely to be regarded as having severe mental health problems than girls. Overall $20 \%$ of children experience problems in one of four age groups $(3,5,7 \& 11$ years old) but only $1.5 \%$ across all four groups. Their study did not report on deaf children because of the small number involved.

Most primary schools in the UK do not have a school counselor though one in five children will have need of counseling during the first eleven years of schooling [42]. Behaviour disorder in deaf children can result from inadequate socialization and communications if born into a hearing family. Young et al. [43] and others [21] have highlighted the criminal vulnerability of deaf individuals because of their criminal suggestibility when dealing with hearing people in authority, which has implications for deaf children and school authority figures, a hypothesis that needs testing.

\subsection{Physical Abuse}

In cases where deaf children are exposed to abuse, there appears to be limited awareness of the extent to which specialist knowledge of cultural interest is required for deaf children [44] and as such a child's impairment could mask child protection concerns [45]. Similarly it is difficult for children to disclose physical, sexual or emotional abuse because of their fear of the abuser and being mis-understood [46]. Being subjected to any physical, sexual or emotional abuse is likely to affect children's academic performance over time as well as their long term mental health. Sexual and physical abuse in early childhood can lead to serious mental health issues especially when children cannot express their feelings to the authority figures. Ridgeway [47] highlighted the number of deaf children suffering from sexual abuse was far greater than for the hearing population. She reported incidences of penetrative sexual abuse being experienced by $40 \%$ of deaf children ( $65 \%$ girls and $35 \%$ boys) by the time they are sixteen, compared to a $15 \%$ prevalence rate in the non-deaf population. Kvam [48] reported similar data from a large Norwegian sample that deaf females were sexually assaulted more than twice as often as hearing females and deaf boys more than three times as often as hearing males. Once again most victims did not report the abuse to authority figures or their parent. The UK government recently set up a national Independent Inquiry into Child Sexual Abuse (IICSA) into historical cases of sexual abuse by famous individuals such as Jimmy Savile and Rolf Harris. The writer argues that, it may become an issue for deaf adults as more cases become known.

Sullivan and Knutson's [49] extensive study of deaf and hard of hearing $(\mathrm{h} / \mathrm{h})$ children, reported that they have twice the risk for physical and emotional neglect, and almost four times the risk for physical abuse than hearing counterparts. Deaf children are at a higher risk than hearing children because of their physical vulnerability. Jones et al. [50] estimated that disabled children experience a three to four-fold increased risk of abuse compared to their non-disabled children. (It is not proposed here that deafness is a disability). Many people do not consider deafness to be a disability and are staunchly opposed to medical models that conceptualize it in such a way [18]. The point being made is that vulnerability can lead to victimization.

A survey of 108 deaf and 317 American hearing students explored childhood maltreatment between deaf and hearing children; more deaf and hard-of-hearing students (77\%) indicated experiencing some form of childhood maltreatment, compared to $49 \%$ of hearing respondents [51]. In addition, students with more severe hearing loss indicated an increased rate and severity of maltreatment. However, being part of the American Deaf community did prevent some maltreatment [51]. Deaf individuals had higher rates of negative cognitions about themselves, others and the future compared with hearing individuals who had suffered maltreatment with long term implications for mental health [51]. The rate of depression and post-traumatic stress was also higher among deaf students regardless of maltreatment but they showed that active members of the Deaf community reported fewer depressive and P.T.S.D. symptoms.

\subsection{Child Protection}

Approximately $6 \%$ of UK children are classifiable as disabled [52]. Stalker \& McArthur [53] indicated that disabled children were significantly more likely to experience abuse than their non-disabled peers. They make the point that the Criminal Justice System and the services offering treatment often did not take into consideration disabled children's needs and heightened vulnerability. They stated that there was a dirge of knowledge of how disabled children respond to abuse as few studies have sought victims' accounts. Extensive input is required, at both strategy and practice levels, to ensure that children's rights to protection are upheld. Nevertheless, Psychologists and schools should be aware of the risks of non-disclosure by deaf children because of their fear of not being believed and limited 
contact with teaching staff.

It would appear that the chances of disclosure of any deaf child's problems (educational or otherwise) are dependent upon a supportive relationship with a trusted person (to whom the disclosure is made) and good communication support. Deaf children benefit more if they disclose to professional staff rather than family, friends and neighbors [54]. Although some schools had created safe and protective environments for deaf children, professional staff was slow to recognize pupils' increased safety needs [55]. Young et al. [56] raised concerns regarding the quality of services and supports available to deaf children, a situation that has shown significant reductions, largely due to the UK economic 'cutbacks' [57-58]. Taylor et al. [54] argued that the abuse of deaf children is frequently under-reported because of the myths and stereotypes surrounding the abuse. Deaf children can be in constant contact with the authorities yet for their abuse or mental health problem to be undetected. Often deaf children lack a wide range of friends and contacts within their extended family and schools because of a shortage of professional support creating higher vulnerability for harm with associated mental health issues.

\subsection{Social Identity/Interactions}

During adolescence, gender, age, ethnicity, and hearing status affects the development of identity [59] with deaf adolescents having to cope with challenges of being deaf in a sound-dominated environment [60]. Cambra [61] found Deaf adolescents construed identity in terms of personal appearance, their ego and interests, but made fewer references to their peers and social environment than hearing adolescents. Their sense of identity was far narrower socially, due to limited interactions and experiences in the community. Cultural factors and social experiences are important when distinguishing between deaf and hearing identities, as the degree of hearing loss can influence how individuals identify themselves as hearing, $\mathrm{h} / \mathrm{h}$, deaf or Deaf.

Social skills are essential for succeeding in the modern world [62-64]; those who lack them are often rejected by others and are at risk of developing mental health problems that persist during adulthood [65]. Communication difficulties and their peers' lack of awareness regarding their hearing status; deaf adolescents do not always experience positive peer interactions in mainstream schools [66]. Beresford et al. [67] has argued that many deaf children were unable to access mental health facilities and reached adulthood untreated resulting in severely dysfunctional lives often ending up in the care of the adult mental health and forensic services. Dammeyer [68] reported that poor signing or spoken communication skills were associated with psychosocial problems. Many deaf schoolchildren often lack contact with Deaf adults acting as good role models of successful deaf people, such contact could be advantageous to good mental health.

Hearing boys in mainstream education are more accepted and popular than deaf male classmates; however this is not the case for deaf girls [69], which probably mimics the hearing world within the same age groups. Friendship made at school can often be lifelong especially in hearing children unlike friendship for deaf students which is often sporadic $[70,64]$. A lack of sustainable friendships could be a potential identifiable risk for later mental health problems. Berelowitz, et al. [71] argue that a major risk factor is social isolation which can allow abuse to occur and go undetected, although they argue that the risks are poorly understood. Van Eldik [72] reported that Dutch Deaf adolescents in Schools for the Deaf experienced more withdrawn behaviors than their deaf mainstreamed and hearing peers and that experiencing regular interactions in a mainstream school is likely to improve social confidence. In various environmental conditions, adolescents with different hearing status displayed diverse levels of social confidence [38]. In today's Society, it is becoming less frequent for children to engage in initial face-to-face communications because they are increasingly using social media instead. Being nimble with their fingers is becoming more important and possibly less dependent upon their hearing status.

\subsection{Risk Behaviour}

While much of the deaf literature is based upon the USA, less is known of the economically less developed countries. For example, Rusinga [73] examined the perceptions of 50 deaf Zimbabweans aged between 15 - 24 (mean 19) years arguing that deaf people's sexual needs are scantily understood and being neglected puts them at risk of sexual health problems as well as sexual violence. Some $36 \%$ of female respondents reported that they had been sexually assaulted while more than a third of females stated if raped they would not report it because they would be too shy or afraid. However deaf adolescents' sexual vulnerability was inextricably linked to their poor sexual socialization and ignorance rather than their deafness [73].

As adolescent males constitute a high suicide risk, they [38] argued that it was essential to undertake further research in the light of deaf people having a $40 \%$ lifetime prevalence of mental health problems, compared with $25 \%$ of hearing people [74]. The reduction of funding of adolescent mental health treatment will have some serious implications for deaf adolescents. Research into the Deaf community is essential to identify methods to reduce the risk of mental health problems arising, an issue under-researched by psychologists.

\section{Physical Health Issues}

According to Alexander et al. [75], deaf patients have poorer health compared to the hearing population and are likely to have a higher rate of hypertension, obesity and depression [76] with poor diagnosis and a lack of adequate 
treatment of chronic conditions putting them at risk of preventable ill health. Deaf adults use primary care more frequently than the general population, although many (44\%) experienced difficulties during their last GP interaction [77]. Deaf people (14\%) rated their family doctor (GP) as poor or very poor compared to $3 \%$ of hearing patients with only a quarter of deaf patients trusting their GP. A similar response is likely to be reported by adolescents if asked; which makes their disclosure of any mental health problems difficult. Emond et al. [77] argue that reasonable adjustments are clearly not always being made for deaf patients under the Equality Act [78]. It is against NHS policy to ask family members to sign/ interpret in GP-patient interactions.

\section{Discussion}

Psychosocial theories of stigma, language and prejudice can help to explain the transformation of deafness from a stigma to a more acceptable cultural identity leading to group and individual identity. These theories can be applied to the issues of deafness as culture: the role of the stigma of 'disability', the use of sign-language, and prejudice against non- group members in the preservation of the Deaf culture. Historically deafness was perceived as a physical disability with cognitive and motor impairments. Deafness as a disability has been the underlying premise of the education and rehabilitation of the deaf for decades [79-80] As Butler, Skelton and Valentine [81] argued deafness is not pathology and does not need to be "fixed".

When deafness is viewed as a disability, then deaf individuals are regarded as lacking a 'normal' attribute. To maintain self-esteem individuals must regard stigmatization as positive [81]). It has been argued that when individuals identify with others who have "disabilities" they do not regard themselves as stigmatized, but as members of a select group [81]. The establishment of an "out-group" is a natural response to development of an "in- group." and is a risk for deaf children isolated in the mainstream schools as most live the majority of their time in the hearing world. Less prejudice from the hearing world would increase the permeability of the culture and weaken its distinctiveness and status. However some Deaf people are opposed to hearing professionals working in the area of deafness Lane [82].

Linguistics is an essential element of culture and heritage, and that people identify more with people who speak the same language than with those who share the same familial background [83]. While Dolnick [84] succinctly argue that "deaf children acquire a sense of cultural identity from their peers rather than their parents" (p. 38). As Goffman [85] defined an individual becomes stigmatized "[when they are] reduced in our minds from a whole and usual person to a tainted, discounted one". Psycho-social theories help to explain the nature of stigma, language and prejudice that has led to formation of the Deaf Community as a minority group. Being stigmatized can lead individuals to form groups composed of like-minded people. A necessary requirement is to create good self-esteem. Some Deaf people seek to separate themselves from the societal concept of disability altogether thereby removing the stigmatizing label. So with in mind to be successful the deaf child should have sense of culture that overarches with the hearing world.

Deaf mental health services often reveal Deaf individuals whose mental illnesses have been significantly neglected, to their risk and detriment and a risk to Society. Denmark [86] identified the frustration deaf individuals feels in trying to communicate is often released as an "explosive reaction" and may be mistaken for mental illness [86].

Psychologists have much to offer deaf children in schools and even before starting education, for example undertaking detailed psychometric assessments for modifying circumstances to enhance deaf children's academic aspirations. Psychology needs to appropriate a range of psychometrics for assessing deaf people. Some non-verbal measures are available such as Raven's Progressive Matrices, BSL versions of the Patient Health Questionnaire, the GAD 7-Item Scale, and the Work and Social Adjustment Scale [87]. The Flesch score [88] is a useful test of readability that should be considered for deaf children who traditionally have a reading age of around nine years old. It can assess if deaf children can read documents placed in front of them. The lower the Flesch score, the harder a document is to read, therefore schoolbook authors and others should aim for a very high figure to enable a larger population to be able to read their material. Some communication software has an inbuilt Flesch Score calculator enabling writers to gain feedback of the readability of their text. Higher readability could reduce the stress for many deaf children.

Psychologists need to be aware of the physical and psychological risk that deaf children experience in schools as well as being aware of the legal issues involved. There is a need for schools to fit adequate systems to alert deaf children (and staff) of possible danger. Fire alarms need to flash or vibrate and smoke detectors need to be adapted so deaf schoolchildren are made aware quickly that they need to move. The vibrating options on many 'smart phones' could be useful to communicate important messages to deaf children

It is important to address the prevention of abuse of deaf children as this is a much under-researched area [54]. MacKay [89] argued for the use of a systematic evidence based approach in response to mental health problems in schools.

Szarkowski \& Brice's [90] qualitative study of 11 parents of deaf children, reported some powerful positive values regarding their deaf children such as accepting it as a learning experience, appreciating everyday positives, taking less for granted and enjoying their unique situation. While criticism can be levied at the study, it does nevertheless look at the situation from a parental aspect with more positive conclusions than the study [91] who argued that as a consequence of a lack of understanding of deaf children's different communications needs, hearing parents can become 
overprotective and over-controlling, which may subsequently interfere with the development of healthy attachments.

Sessa \& Sutherland [18] reviewed the role of the four National Deaf ' Child \& Adolescent Mental Health Services' (CAMHS) providing support for deaf children and their families to encourage normal development thus reducing the mental health risk and improve children's sense of inclusion and self-esteem. Deaf CAMHS aim to reduce the risks of deaf people with untreated mental illnesses, preventing admission to the Criminal Justice and the psychiatric system. They [18] argued that many professionals do not know about the units as they are still relatively new facilities for the treatment of mentally ill deaf children.

As to the treatment or prevention of mental illness, more could be undertaken in terms of training school professionals regarding deaf children's vulnerability when they engage in 'safeguarding training'. However given that Education is now facing rounds of 'cuts' after being 'protected' for so long it is not clear how this need will be funded.

From a teaching viewpoint it is interesting to ask what impact does being deaf in an unsympathetic hearing environment have on the behaviour of the child. Do they 'play up' more? Are there more outbursts of frustration and anger, especially as most teachers are not trained to deal with a deaf child in this situation? While technology can help deaf children, there may well be a tendency to retreat into the online world (but any more than hearing children?). Or can technology help a child who has issues communicating in a non-signing world understand or be understood more easily with the use of 'I-pads and tablets' with details of lessons would help as would access to the internet?

In addition to school funding, there is a need for parental support for pre-school deaf children to enable them to start school at the same academic level as hearing children. It is essential that where anxieties exist that early detection and parent support is provided. For example, the Distraction Test can be used with newborn up to 9 months old babies (www.gosh.nhs.uk) to help identify hearing loss. There is a need to up-skill other professionals who support the emotional and psychological welfare of deaf children, which could be undertaken by Psychologists to facilitate a culture of improved language acquisition for deaf children to prevent negative mental health outcomes.

\section{Future}

There are a limited number of psychologists who can sign or are willing to work in the area and learn to sign. This highlights the weakness of deaf psychometrics especially if the items are being filtered through interpreters (often not psychometrically orientated), who add their own slant to it, usually unknowingly. Cromwell [92] explored the difficulties that hearing psychologists face when testing deaf patients and also how interpreters can affect this process. As more deaf students are gaining university education, there is an increasing number of deaf individuals working as professional psychologists. This under-reported and under-funded sector could be a growth area for Psychologists. Working with deaf individuals challenges many of the practices and customs of mainstream psychology but is professionally rewarding if psychologists can help reduce the mental health problems experienced by children in our schools. Ironically, better identification of deaf children means that the problem will not go away. Psychologists are in a good position to increase deaf awareness in pupils and staff by running courses, staff support and evidence based therapy.

Ideally deaf children should have a solid progression into adulthood with an appropriate physical and mental good health, a high level of social independence, being able to maintain good and meaningful emotional relationships based upon good communication skills irrespective of method (signing or cochlear implant) and be proud of being D/deaf. Unfortunately, many deaf individuals are discriminated against in the community. This is likely to continue until there are radical changes in the approach adopted by the government bodies as well as the professions. This leads to the question "If mental illness is usually regarded as being under-funded in most countries' health budgets, where does that leave the $\mathrm{D} /$ deaf child/patient? While there are major differences between the provisions of services in the UK, the issues faced by deaf schoolchildren are similar to that of many of the developed world (social isolation, health problems, and restricted careers) with modern technology their world could change for the better.

\section{Recommendations}

To overcome some of the issues rose in this paper; it is argued that there needs to be governmental and professional initiatives to increase the:

a) Deaf awareness in mainstream education.

b) Awareness of the risk of abuse faced by deaf children.

c) Funding for the training of more professional interpreters with an increase in the centers offering BSL training for staff and pupils.

d) Funding for Universities to train professionals and students to be deaf aware (e.g. Medicine, Law, Social Work, Education and Psychology).

e) Training for BSL interpreters to include child protection awareness training and those who are interpreting child protection legal cases should have access to specialist child protection and legal training.

f) Awareness that deaf children should not be excluded from sport activities or education classes.

g) Use of professional interpreting services when facilitated communication is needed and not to rely on family members to sign for deaf children because they are often an inhibiting factor for deaf children. 
h) Fitting of safety alert systems including personal vibrating bleeps to help reduce pupils' anxiety and relieve stress. Make schools 'deaf friendly' with flashing lights and Loop systems for those would benefit from such equipment.

i) Funding for specialist support services so that all deaf children have an equal opportunity as any other child irrespective of their Postcode (zip code).

j) Funding for more psychologists to work in children's mental health.

k) Increase awareness of the cultural needs of the Deaf Community by challenging such discriminatory views held by the establishment regarding the ability of deaf people to play an active role in Society.

\section{Conflict of Interest}

The author received no financial support for the research or authorship of this article and has no conflict of interest.

\section{Acknowledgements}

I would like to thank Tommy MacKay, Leanne Dobson \& Annmarie Moran for their comments on an earlier draft of this paper.

\section{REFERENCES}

[1] B. Wright, The cognitive and behavioural complications of deafness. In The Cognitive and Behavioural Abnormalities of Paediatric Diseases (eds. R. Nass \& Y. Frank). Oxford, England: Oxford University Press, 2011.

[2] Consortium for Research into Deaf Education, CRIDE report on 2015 survey on educational provision for deaf children. www.ndcs.org.uk/CRIDE, 2015.

[3] H.M. Fortnum, A.Q. Summerfield, D.H. Marshall, A.C. Davis, J.M. Bamford, Prevalence of permanent childhood hearing impairment in the United Kingdom and implications for universal neonatal hearing screening: questionnaire based ascertainment study. BMJ, 323, 536-40, 2001.

[4] Action on Hearing Loss, www.actiononhearingloss.org.uk, 2017.

[5] National Deaf Children's Society, Post-16 education data on deaf young people: A National Deaf Children's Society briefing-12th January 2016. http://www. ndcs.org.uk, 2016.

[6] Department of Education, Revised GCSE and equivalent results in England, 2014 to 2015. SFR 01/2016, 21 January 2016. London, England: Her Majesty's Stationery Office, 2016.

[7] University Central Council on Admission (UCCA).

[8] National Deaf Children's Society, About N.D.C.S., http:// www. ndcs.org.uk, 2011.
[9] D.F. Moores, in D.F. Moores (1996). Educating the Deaf: Psychology, Principles, and Practices, Illinois: Houghton Mifflin Company, 1987.

[10] S. Gregory, Bilingualism and the education of deaf children, Paper presented at the Bilingualism and the education of deaf children: advances in practice Conference, Leeds, June 1996.

[11] W.M. McCord, J. McCord, The psychopath: an essay on the criminal mind. Princeton: N.J. Van Nostrand, 1964.

[12] L.N. Robin, R.K. Price, Adult disorders predicted by childhood problems: Results from NIMH epidemiology catchment are project. Psychiatry.54, 116-132, 1991.

[13] S. Austen, E. Coleman, Controversy in deafness: Animal farm meets Brave New World. In S. Austen \& S. Crocker (Eds.) Deafness in Mind: Working Psychologically with Deaf People across the Lifespan. London, England: Whurr, 2004.

[14] B.T. Monteiro, T. McNeeney, 'Forensic Aspects of Deafness', in Proceedings of the Second International Congress (1991), Namur, Belgium, 1992.

[15] U.K. Council of Deafness, Information Sheet. London, England: U.K. Council of Deafness, 2000.

[16] Action on Hearing Loss. www.actiononhearingloss.org.uk, 2016.

[17] S. Powell, Personal Communication of $11^{\text {th }}$ September 2014

[18] B. Sessa, H. Sutherland, Addressing mental health needs of deaf children and their families: the National Deaf Child and Adolescent Mental Health Service. The Psychiatrist, 37, 175-178, 2013.

[19] T. Humphries, P. Kushalnagar, G. Mathur, D.J. Napoli, C. Padden, C., Rathmann et al., Language acquisition for deaf children: reducing the harms of zero tolerance to the use of alternative approaches. Harm Reduct J., 9, 16, 2012.

[20] L.N. Wauters, W.H.J. van Bon, A.E.J.M. Tellings, Reading comprehension of Dutch deaf children. Reading and Writing: An Interdisciplinary Journal, 19, 49-76, 2006.

[21] M.J. Berry, J.E. Brown, Some aspects of possible vulnerability of Deaf people in the Forensic World. Forensic Update, 85, 25-33, 2006.

[22] M. Strong, Language Learning and Deafness. Cambridge: Cambridge University Press, 2007.

[23] Education Act (1944) [7 \& 8 Geo 6 c31], London, England: Her Majesty's Stationery Office.

[24] H. Fortnum, P. Stacey, G. Barton, Q. Summerfield, National evaluation of support options for deaf and hearing-impaired children: Relevance to education services. Deafness and Education International, 9, (3), 120-130, 2007.

[25] Y. Bat-Chava, E. Deignan, Peer relationships of children with cochlear implants. Journal of Deaf Studies and Education, 6, 186-199, 2001.

[26] B.A. Kent, Identity issues for hard-of-hearing adolescents aged 11, 13, and 15 in mainstream settings. Journal of Deaf Studies and Deaf Education, 8, (3), 315 - 324, 2003.

[27] R. Punch, M. Hyde, The social participation and career decision-making of hard-of-hearing adolescents in regular 
classes. Journal of Deaf Studies and Deaf Education, 7, (3), 122-138, 2005.

[28] N. Israelite, J. Ower, G. Goldstein, Hard-of-hearing adolescents and identity construction: Influences of school experiences, peers, and teachers. Journal of Deaf Studies and Deaf Education, 7, (2), 134-148, 2002.

[29] T. Most, A. Wiesel, T. Blitzer, Identity and attitudes towards cochlear implant among deaf and hard of hearing adolescents. Deafness and Education International, 9, (2), 68-82, 2007.

[30] T. MacKay, Educational and psychological outcomes for children with cochlear implants. Educational and Child Psychology, 27, (2), 50-57, 2010.

[31] C.J. Newschaffer, L.A. Croen, J. Daniels, E. Giarelli, J.K. Grether, S.E. Levy et al., The epidemiology of autism spectrum disorders. Ann Rev Public Health, 28, 235-58, 2007.

[32] 32. A. Geers, E. Tobey, J. Moog, C. Brenner, Long-term outcomes of cochlear implantation in the pre-school years: From elementary grades to high school. International Journal of Audiology, 47, (2), 21-30, 2008.

[33] A. Geers, J. Nicholas, Enduring Advantages of Early Cochlear Implantation for Spoken Language Development. Journal of Speech, Language, and Hearing Research, 56, 643-653, 2013.

[34] National Institutes of Health (2014). Publication No. 11-4798, Statistics Partial Update, August, 2014. http:// www.nided.nih.gov.

[35] C. Raine, Cochlear implants in the United Kingdom: Awareness and utilization. Cochlear Implants Int. 2013 Mar; 14 (Suppl 1): S32-S37, 2013.

[36] Central Manchester Health (2016). Cochlear Implants. www.cmft.nhs.uk/childrens-hospitals/our-services.

[37] S. Ridgeway, I'm happy my child is deaf [interview by Merope Mills]. The Guardian Newspaper, $\left(9^{\text {th }}\right.$ April $)$, London, England, 2002.

[38] M.J. Berry, L. O'Rourke, Hearing, Deaf and Cochlear Implanted Adolescent Males' Social Confidence (C.I. Males are not Confident in the Presence of Deaf Males). Universal Journal of Psychology, 3, (4), 113 - 121, 2015.

[39] T.A. Zwolan, K. Henion, P. Segel, C. Runge, The Role of Age on Cochlear Implant Performance, Use' and Health Utility: A Multicenter Clinical Trial. Otology \& Neurotology, 35, 9, $1560-1568,2014$.

[40] F. Bathgate, E. Bennett, J. Cropper, L. Edwards, A. Emond, C. Gamble, R. Kentish, V. Samuel, Good practice guidelines for clinical psychologists working in paediatric cochlear implant teams, Cochlear Implants International: An Interdisciplinary Journal. 14, 4, 32-34, 2013.

[41] L.M. Gutman, H. Joshi, M. Parsonage, I. Schoon, Children of the New Century: Mental health findings from the Millennium Cohort Study. Centre for Mental Health-Report UCL Institute of Education. www.centreformentalhealth.org.uk, 2015.

[42] Children's Mental Health Matters, Provision of Primary School Counselling. www.Children Mental Health Week.org. February 2016.

[43] A Young, B. Monteiro, S. Ridgeway, "Deaf people with mental health needs in the criminal justice system: a review of the UK literature." The Journal of Forensic Psychiatry, 11 (3), $556-569,2000$

[44] A Young, R. Hunt, C. Smith, The Impact of Integrated Children's Services on the Scope, Delivery and Quality of Social Care Services for Deaf Children and Families Phase 1 Report. The University of Manchester. www.ndcs.org.uk, 2008.

[45] M. Murray, C. Osborne, Safeguarding Disabled Children: Practice Guidelines. London, England: The Children's Group, 2009.

[46] D Allnock, P. Miller, No one noticed, no one heard: a study of disclosures of childhood abuse. London, England: N.S.P.C.C., 2013.

[47] S. Ridgeway, Psychological Health and Well-being - Abused Deaf Children and Adults, Unseen Secrets Conference, London, England, 1998.

[48] M.H. Kvam, Sexual abuse of deaf children. A retrospective analysis of the prevalence and characteristics of childhood sexual abuse among deaf adults in Norway. Child Abuse \& Neglect, 28, 3, 241-251, 2004.

[49] P.M. Sullivan, J.P. Knutson, Maltreatment and disabilities: A population-based epidemiological study, Child Abuse \& Neglect, 24(10):1257-73, 2000.

[50] L. Jones, M. Bellis, S. Wood, K. Hughes, E. McCoy, L. Eckley, G. Bates, C. Mikton, T. Shakespeare, A. Officer, Prevalence and risk of violence against children with disabilities: a systematic review and meta-analysis of observational studies. The Lancet 380, 9845, 899-907, 2012.

[51] Rochester Institute of Technology, Abuse rates higher among deaf and hard-of-hearing children compared with hearing youths, study finds. ScienceDaily. www.sciencedaily. com/releases/2011/01/110118154733.htm, 7 February 2011.

[52] D. Miller, J. Brown, 'We have the right to be safe' - Protecting disabled children from abuse. London, England: N.S.P.C.C., 2014.

[53] K. Stalker, K. McArthur, Child abuse, child protection and disabled children: a review of recent research. Child Abuse Review, 21, 24-40, 2012

[54] J. Taylor, A. Cameron, C. Jones, A. Franklin, K. Stalker, D. Fry, Deaf and disabled children talking about child protection. N.S.P.C.C.: London, England 65p, 2015.

[55] Ofsted, Protecting Disabled Children: Thematic Inspection. resources / protecting-disabled-children-thematic-inspection. http://www.ofsted.gov.uk., 2012.

[56] A. Young, R. Hunt, R. Oram, C. Smith, The Impact of Integrated Children's Services on the Scope, Delivery and Quality of Social Care Services for Deaf Children and Their Families: London, England, 2009.

[57] Action for Children, The Red Book 2013: Children under Pressure. http://www action for children.org.uk/media /7562887/red-book-2013.pdf., 2013.

[58] K. Stalker, C. MacDonald, C. King, F. McFaul, C. Young, M. Hawthorn, We could kid on that this is going to benefit the kids but no, this is about funding: cutbacks in services to disabled children and young people in Scotland. Child Care in Practice 21, 1, 6-21, 2015.

[59] A. Weisel, An opening statement: identity development and Deaf education. In A. Weisel (Ed.), Insights into deaf 
education: Current theory and practice (pp. 11-25). Tel Aviv, Israel: Academic Press of Tel Aviv University, 1998.

[60] I.W. Leigh, D. Maxwell-McCaw, Y. Bat-Chava, J.B. Christiansen, Correlates of psychosocial adjustment in deaf adolescents with and without cochlear implants: A preliminary investigation. Journal of Deaf Studies and Deaf Education, 14, (2), 244-259, 2009

[61] C. Cambra, Feelings and emotions in deaf adolescents. Deafness and Education International, 7, (4), 195-205, 2005.

[62] G.V. Caprara, C. Barbaranelli, C. Pastorelli, A. Bandura, P.G. Zimbardo, Prosocial foundations of children's academic achievement. Psychological Science, 11, (4), 302-306, 2000.

[63] C. Malecki, S. Elliott, Children's social behaviors as predictors of academic achievement: A longitudinal analysis. School Psychology Quarterly, 17, 1-23, 2002.

[64] G. Batten, P.M. Oakes, T. Alexander, Factors Associated With Social Interactions between Deaf Children and Their Hearing Peers: A Systematic Literature Review. Journal of Deaf Studies and Deaf Education, 19, 3,285-302, 2014.

[65] L. Elksnin, N. Elksnin, Teaching emotional skills at school and home. Denver, CO: Love, 2006.

[66] A. Eriks-Brophy, A. Durieux-Smith, J. Olds, E. Fitzpatrick, C. Duquetter, J. Wittingham, Facilitators and barriers to the integration of orally educated children and youth with hearing loss into their families and communities. The Volta Review, 107, 5-36, 2007.

[67] B. Beresford, V. Greco, S. Clarke, H. Sutherland, An Evaluation of Specialist Mental Health Services for Deaf Children and Young People. Social Policy Research Unit, York: University of York, 2008.

[68] J. Dammeyer, Psychosocial development in a Danish population of children with cochlear implants and deaf and hard-of-hearing children. Journal of Deaf Studies and Deaf Education, 15, (1), 50-58, 2010

[69] N. Wolters, H.E. Knoors, A.H. Cillessen, L. Verhoeven, Predicting acceptance and popularity in early adolescence as a function of hearing status, gender, and educational setting. Research in Developmental Disabilities, 32, 6, 2553-2565, 2011.

[70] T. Nunes, U. Pretzlik, J. Olsson, Deaf children's social relationships in mainstream schools. Deafness and Education International. 3 (3), 123-136, 2001.

[71] S. Berelowitz, J. Clifton, C. Firimin, S. Gulyurtlu, G. Edwards, If only someone had listened. The Office of the Children's Commissioner's Inquiry into Child Sexual Exploitation in Gangs and Groups. London, England: Office of the Children's Commissioner, 2013.

[72] T. Van Eldik, Mental health problems of Dutch youth with hearing loss as shown on youth self-report. Annals of the Deaf, $150,1,11-16,2005$.

[73] O. Rusinga, Vulnerability of Deaf Youths to Sexual and Reproductive Health Problems. African Journal of Reproductive Health. 16, 2, 271-282, 2012.

[74] Department of Health, Mental Health and Deafness, Towards Equity and Access. London, England: NIMHE, Her Majesty's Stationery Office, 2005.
[75] A. Alexander, P. Ladd, S. Powell, Deafness might damage your health. Lancet 379, 979-981, 2012.

[76] A. Emond, M. Ridd, H. Sutherland, L. Allsop, A. Alexander, J. Kyle, The current health of the signing Deaf community in the UK compared with the general population: a cross-sectional study. BMJ Open 2015;5:e006668, $2015 \mathrm{a}$.

[77] A. Emond, M. Ridd, H. Sutherland, L. Allsop, A. Alexander, J. Kyle, Access to primary care affects the health of Deaf people. British Journal of General Practice. 65, 631, 95-6, $2015 \mathrm{~b}$.

[78] The Equality Act (Amendment) Order 2010, London, England: Her Majesty's Stationery Office.

[79] H. Lane, Construction of deafness. In L. Davis (Ed.), The disability studies reader (pp. 153-171). New York, NY: Routledge, 1997.

[80] R. Butler, T. Skelton, G. Valentine, Language barriers: Exploring the world of the deaf. Disability Studies Quarterly, 21(4), 42-52, 2001

[81] S. Linton, Claiming disability. New York: New York University Press, 1998.

[82] H. Lane, The mask of benevolence. New York, NY: Alfred Knopf, 1992.

[83] H. Giles, R.Y. Bourhis, D.M. Tayler, Toward a theory of language in ethnic group relations. In Monograph: Language Ethnicity and Intergroup Relations. New York, NY: Academic Press 1977.

[84] E. Dolnick, Deafness as culture. The Atlantic Monthly, September, 37-53,1993

[85] E. Goffman, Selections from stigma. In L. Davis (Ed.), The disability studies reader (pp. 203-215). New York, NY: Routledge, 1997.

[86] J. Denmark, Mental Illness and early profound deafness. Brit. J. Med. Psychol., 39, 117-124, 1966.

[87] K. Rogers, A. Young, K. Lovell, M. Campbell, P. Scott, S. Kendal, The British Sign Language Versions of the Patient Health Questionnaire, the Generalized Anxiety Disorder 7-Item Scale, and the Work \& Social Adjustment Scale. Journal of Deaf Studies and Deaf Education, 18, 1, 110-122, 2013.

[88] T. MacKay, Educational psychology: The fall and rise of therapy. Educational and Child Psychology, 24, (1), 7-18, 2008 .

[89] R. Flesch, A new readability yardstick. Journal of Applied Psychology, 32, 221-223, 1948.

[90] A. Szarkowski, P.J. Brice, Hearing Parents' Appraisals of parenting a Deaf or Hard-of-Hearing Child: Application of a Positive Psychology Framework. Journal of Deaf Studies and Deaf Education, 1-10, 2016.

[91] L. Edwards, S. Crocker, Psychological Processes in Deaf Children with Complex Needs: An Evidence-Based Practical Guide. London, England: Jessica Kingsley Publishers, 2008.

[92] J. Cromwell, Deafness and the art of psychometric testing. The Psychologist, 18, (12), 738-740, 2005. 